\title{
Affect and Agency in Modern Warfare Videogames: Feeling the Muslim Enemy
}

\author{
Giuseppe De Riso \\ University of Naples 'L'Orientale' \\ gderiso76@gmail.com
}

\begin{abstract}
The aim of this paper is to discuss the acted or performed dimension through which Western warfare videogames are employed in the creation of culturally divided identities. During the interaction, affects and emotions are channelled in order to shape subjects acritically embracing Western values, while also driving a larger process of construction of a generic Muslim enemy. On the one hand, Middle-Eastern subjects work as agents of a polarizing process which prompts users' aggressive reaction; on the other, whole Middle-Eastern cities and regions are being re-created as three-dimensional spaces, and then digitally stored to expand huge terrestrial and cultural databases. These function on two levels: first, as virtual training grounds for prospective soldiers, and secondly as affective maps providing cultural coordinates as to how Muslim territory is to be felt and, consequently, lived.
\end{abstract}

\section{Home war}

The aim of this article is to discuss those processes through which videogames, and especially those which can be experienced from a first person perspective, contribute to the emergence of cultural identity. Games and war simulations play a significant role in the military strategies currently employed in the conflicts which have the Persian Gulf as their epicentre. When NATO and Israel began preparations for military actions against Iran in May 2003, part of the American army had already envisaged and 
participated in a computer-simulated third world war scenario. The war in Iran had indeed been planned as a global strike, ${ }^{1}$ coordinated by the US Strategic Command, which had required several virtual simulations for the training of American armed forces, many of which are at present classified. One of the few which are publicly known, called 'Theater Iran Near Term', simulated a total bombing of the Iranian territory with the purpose of eliminating prime targets as part of a strategy commonly known by the name of 'Shock and Awe' (Galloway, 2006: 70). The phrase refers to a military tactic used to pre-emptively dissuade an enemy from taking aggressive action through a brutal ostentation of one's own fire power.

In about the same period Kuma/War! (Kuma Reality Games, 2003) and America's Army (U.S. Army, 2002) two war games developed with the involvement of the American Department of Defense (DoD for short) were freely published. The former is an episodic first person shooter (or FPS, a videogame genre experienced directly from the eyes of the player's avatar) offering reconstructions of the most important American military events in playable form. In the mission called 'Uday and Qusay's Last Stand', for example, one can take part in the final battle in which Saddam Hussein's sons were killed, while in the one called 'The Death of Osama Bin Laden' it is possible to experience the killing of Osama Bin Laden. The game offers a total of 108 missions, expanded through updates which are freely downloadable from the Internet, most of which are set in Iraq, Afghanistan and Iran. Verisimilitude and timeliness in the supply of new missions serve to strengthen the players' perception of witnessing real events, and it is no coincidence that the advertising trailer, whose transcript is reported below, strongly emphasizes this combination:

From the headlines to the frontlines, we put you there! Introducing Kuma/War!, an intense, boots-on-the-ground experience of actual news events occurring around the world right now. Real world news, real world games. Subscribe to Kuma/War! and each month you'll get playable missions delivered to your computer. Intense, episodic play based on the very same stories rocking the world today. Kuma's news team takes you through the top stories with expert analysis including Major-General Thomas L. Wilkerson and the critical intel you need to understand the world in crisis. After we report it, you play it. In single-player and multi-player, you devise the tactics, you make the hard choices. We create the news as it happens, [...]. With Kuma you experience the toughest fighting of the world. You are the 4th Infantry Division capturing Saddam. [...] Wherever the war takes our forces, we'll put you there, on the ground and in the thick of it. Accurate and authentic; intense and immersive; constantly updated to be timely and real. February 2004 gaming grows up. ${ }^{2}$

The emphasis on the accuracy of the reconstructions, and especially on how quickly they follow their corresponding military operations, is apparent. The events witnessed in Kuma/War! seem loyal to documentary practice in their purportedly allowing players to live war experiences almost simultaneously to their occurrence. The game's updates have hitherto seamlessly blended with news reports of the war in Iraq. For example, Kuma sponsored Fox News' coverage of the "war on terror" in the US to give the 
impression that their playable missions represented live or documentaristic reconstructions of wartime events. In like manner, America's Army is a free strategic FPS released in July 2002 in which many scenarios blend imaginary elements with accurate situational and topographical reconstructions of the most significant military interventions in Iraq, Libya, Pakistan or Lebanon, such as the liberation of Jessica Lynch. $^{3}$

Both simulations represent manifest government propaganda aimed at spreading military topics in mass culture. The discourses of power active in them try to foster the chauvinistic spirit of western players by addressing especially those countries placed in the grey zone of the middle eastern belt as primary targets of a complex disparaging campaign. Indiscriminately labelled as Arab world, they are identified as the expression of that kind of backward-looking, fundamentalist and intolerant Islamism which the West has historically proclaimed as its natural enemy. Michael Macedonia, former Chief Technology Officer for the US Army Program Executive Office for Simulation, Training, and Instrumentation, ${ }^{4}$ has stated that, at about the end of last century, the American DoD felt the need for a cooperation with the videogame industry (Korris, 2007: 425). On the one hand, the simulations they had been using for military training boasted extreme realism, which was useful to prepare soldiers for real combat situations; on the other, they were not particularly compelling or exciting for the new generation of men and women joining the army, since most of them were videoplayers. According to statistical data of the DoD, as many as $90 \%$ of those joining the army declared to be a videogamer, and $30 \%$ of them even defined themselves as hardcore or experienced players (425). What the $\mathrm{DoD}$ found tempting about videogames, among other things, was their ability to create virtual worlds which were both immersive and exciting.

\section{A metaphysics of feeling}

If, in the words of Marshall McLuhan, "the effects of technology do not occur at the level of opinions or concepts, but alter sense ratios or patterns steadily and without any resistance" (1964: 15), then a theoretical approach focused on representation does not appear to allow an adequate description of the discourses of power active within the digital apparatus. In fact, the necessity of the players' bodily participation to the games involves an enacted or performed element which elicits a qualitative modulation of affect. These games bring their images close to the player's body, in adherence or continuity with it in such a way that it becomes necessary to register those affects brought about by the feeling of proximity or physical presence of the other. That's why videogames discussed here won't be described simply in terms of representation, as vehicles of meanings associated to visual impressions, but above all as events or "extended doing, a performance with effects" (Butler, 1997: 7), especially with regard to the kind of 'nonsemantic movements' which Derrida described as follows: 
[...] a tremor, a shock, a displacement of force [...] that is propagated, transmitted. What takes place, in this sense, what is transmitted, communicated, does not involve phenomena of meaning or signification. In these cases we are dealing neither with a semantic or conceptual content, nor with a semiotic operation, and even less with a linguistic exchange. (1997: 1)

Central to the approach adopted here are the concepts of 'affect' and 'technicity' put forward respectively by Brian Massumi $(2002 ; 2011)$ and Mark Hansen (2006) as a possible prospect for performance theory and Cultural Studies in general. Their starting point is the observation that human body schema are naturally 'in excess' of themselves. The body is not a single and closed entity, as the sense of vision would suggest, but an open device merged with its environment by virtue of its ability to analogically transform what it comes into 'contact' with. It is the case, for example, of light waves converted by the sense of vision into images, which are in turn converted into imagination; or of the transformation of thermal energy into heat sensations, be them pleasant or painful, which can then be coded through art. Mark Hansen uses the expression 'mixed reality' (2006: 1) to refer to the primacy of the analogue in considering the body as an opening, a transformative-productive intersection among the countless planes of reality. With this expression Hansen means to highlight the active involvement of the body as a transformative threshold turning sensation into thought and perception. The 'transductive' faculty of the human body, to use a term from Massumi (2002: 76), transforms sensations allowing them to continue among different qualitative states of the real. Massumi also uses the acronym RAO (Random-Access Opening) to describe the natural condition of the body:

The body as RAO (random-access opening) can connect in any number of ways to itself, its objects, and other bodies. It can open, split, and reconnect at any point, inside or out. It is no longer an objective volume but an extendability. Its dimensionality has increased beyond the three of spatial presence: from the three dimensions of the voluminous it leaps to a fifth dimension of the extensile. This dimension is actually fractal, between dimensions. Split and extend: the basic operation used to generate fractal figures. The fractalization of the body is no metaphor. It is an operation: the posthumanizing operation. The operation of fractalization is posthumanizing because, featured prominently among its 'and's', is subject and object. (127)

From this perspective, it becomes possible to see how vision does not refer only to the conversion of visual impressions into images, but to a vision in act. What is seen is not so much a passive 'object' of the gaze, endowed with specific shapes and colours, as a dynamic event perceived abstractly and based on the accumulation of affect where initial visual impressions 'continue' through the effects that they produce on the body. Vision and its effects are inseparable. This helps to understand the epistemological delusion of western thought, which from the advent of Socratic and Neoplatonic philosophy, has shaped the activity of the intellect around the functioning of vision. The epistemological practice which has ensued, also known as ocularcentrism, consists in the separation, reorganization and crystallization of the real into 'objects' of knowledge, 
on whose qualities the attention of the subject is directed. Emphasis on the properties of objects has thus imposed the logic of representation and meanings, at the expense of the abstract movement of sensation which nonetheless constitutes an essential function of human perception understood as an event.

This becomes especially relevant with regard to the interface employed in first person shooters videogames, since they are based on the recreation of an embodied condition which makes it essential to consider how it feels to be present and move in their virtual spaces. As previously hinted, by the acronym FPS we refer to a kind of videogame in which interaction occurs through a first person perspective, that is to say the user experiences the world as seen directly through the eyes of his or her own avatar within a three-dimensional space. This is a genre which became popular during the first half of the '90s, after the publication of Wolfentein 3D by id Software in 1992 and, above all, of its spiritual sequel, Doom, which came out the following year. Due to the computational limitations of the microprocessors of the time, this kind of visuality was more similar to that of a disembodied eye floating through the simulated environment, as if a camera placed roughly at the level of the virtual body's eye followed its every move.

In time, however, technological development has favoured the tendency to make virtual camera and body merge. The aim is not just the mere representation of visual impressions, but the recreation of the perceptive conditions of the eye understood as a sense organ fully integrated in a body made up of muscles and nerves. In other words, vision is strictly connected with and even constrained by bodily capacity, for example by the reactions of the optic nerve's cells and receptors to light stimuli, or by the effects on vision deriving from proximity to all the other senses, since the eye is placed inside the head, which is in turn bound by the movement possibilities of the muscles of the neck. The screen frame takes into consideration what the body does or suffers, not just what it sees, and since this perspective is based on the absence of cinematic editing, it has the ambition to connect the user also to a pre-subjective or affective regime linked to the avatar's vision and, broadly speaking, to its embodied condition.

In the analysis of such videogames it is therefore not only possible, but also necessary to register the modes through which what is represented in the images on screen 'carries' or transmits invisible structures of meaning together with the agency induced by a particular modulation of affects. As Steven Shaviro wrote with regard to the concept of modulation that had already been introduced by Gilles Deleuze in his Postscript on the Control Societies (1992):

Modulation is the process that allows for the greatest difference and variety of products, while still maintaining an underlying control. [...] modulation [...] is a basic characteristic of digital processes in general. (Shaviro, 2010: 15-16)

In an FPS, images do not offer simply visual representations, but also spaces occupied at a distance by the player. Since users cannot actually see the avatar's body from an external point of view, from a third person perspective, they cannot identify themselves with any particular image. It is necessary, instead, to take one's place; the 
subject becomes one at the moment he locates and singles out his body (since these games are especially intended for male players) in relation to the environment and the objects it contains. What is important is the collocation of the corporeal self in relation to the space in which it is contained. In contrast to cinema, the embodied condition of the player in an FPS introduces a cognitive dimension which complicates the reflection on otherness and the production of meaning by virtue of the motor participation required. The interface provides the player with the sensory clues which facilitate his placing in space, while also determining the quality of the relations with everything which co-habits that very same space. Consequently, it is through the mediation of the interface that the relationship between the avatar's body and its surrounding environment can be formed. The interface, invisible to the player's eyes, seems to have the power to steer the subject's agency which it contributes to establish. That's why the analysis of the interface is especially important in this kind of virtual interaction. In the words of William Connolly, it has the power to change "the relays that connect word, gesture, memory, sound, [...] mobility, image, and thinking" (2002: 102). It hides techniques "both gross and subtle, by which thinking is altered in its direction, speed, intensity, or sensibility" (100).

Indeed, following Brian Massumi (2002) and his explanation of the way in which bodies affect and are affected in a playing field, it becomes possible to see that the interface in an FPS, far from being neutral, appears structured to arise an immediate polarization between self and other at an instinctual level. A typical element on the screen is the presence of the avatar's arm or hand extending prosthetically into the virtual world and holding a weapon. The weapon is strictly related to vision, since it does not matter where the avatar is looking, the weapon will always be visible at the centre of the screen and ready to fire. So, when Muslims appear they are immediately displayed as targets: the interface presents them as aggressors suggesting that they need be quickly eliminated. The weapon becomes thus an instrument of power, a phallic symbol of mastery and domination on space and its objects, creating an immediate and palpable tension between the avatar's body and whoever comes into sight. It turns virtual space into an in-between charged with a tension both attracting and repelling self and other, without them ever meeting each other. The player and the enemies' movements find motivations and applications in the weapon. Depending on the type of weapon and on how it is employed, it can empower or disempower the player's body and his movements, while at the same conditioning the enemies' reactions. The weapon accelerates or delays the development of the action and, more generally, it establishes the perceived qualities of the environment. If the presence of bodies and their arrangement in the fighting area is what drives the player, it is nonetheless the weapon that the latter is holding the true catalyst of the action as a whole, the focal point commanding both the player attention and whomever looms up in front of it.

In this sense, the weapon is only superficially the object of the player, if one looks at it as the instrument employed to affirm one's presence in the world. If, however, we consider the point through which movement is articulated to be the subject, then the weapon itself and not the player is the subject. It is no accident that the weapon is the 
only element which is visually prominent. The person holding the weapon becomes thus its instrument. While it is true that the weapon is used by the player, it is also the case that it is the real driving force of the action, since no other element can produce effects analogous to the quality of the relations within the simulation. What happens on screen is the product of the weapon which like a trigger pulls certain kinds of gestures out of the person holding it. The weapon interpellates the player as subject (autonomous, free and in charge) when the latter is in reality subjected to the former.

It arranges the avatar and the other around itself, defining their roles and the kinds of relationship they can establish. The interface can thus work to oppose two polarities: on the one side the player, who is supposed to acritically and aprioristically embrace the western political creed; on the other the Muslim terrorist, since in these kinds of simulations Islam and terrorism amount to the same thing. Both of them move within a system of attraction and repulsion without any possibility of really knowing each other. An FPS would not exist without this tension, the user would have no reason to move and act if the other were not immediately and unequivocally presented as an opponent. The user's violent reaction is spurred almost mechanically, instinctively, even before any ideological, cultural, political or narrative reason.

People living in the Middle East are all equally reduced to terrorists, differences cancelled; they function first as a felt or perceived quality of fear and only later as bearers of meaning. Muslims function like the 'indexical signs' theorized by Peirce (1988), imperatives or self-executing commands which are immediately performative because of they affect the nervous system. The screen captures the subject by framing the objects of his or her gaze the moment they appear on the scene, thus igniting a polar attraction which is the true driving force of the action:

There is always the nagging potential of the next after being even worse, and of a still worse next again after that. The uncertainty of the potential next is never consumed in any given event. There is always a remainder of uncertainty, an unconsummated surplus of danger. The present is shadowed by a remaindered surplus of indeterminate potential for a next event running forward back to the future, self-renewing. (Massumi, 2010: 7273)

The weapon becomes an impassable barrier which forever bounds the other on the user's horizon as the essentialized evil and irreconcilable opposite. The action alternates bouts of feverish activity, with waves of enemies coming cyclically one after another, with slower resting breaks: a seesaw or pattern whose fluctuations rhythmically punctuate moods and feelings which range from fear to relief. This is only possible in a virtual context which stymies the player's identification with the image on screen (a contingency which would create a detachment between player and image, confining the former to the secure position of spectator), in favour of the 'individuation' of the subject as a body in a given space.

The interface prompts a specific kind of agency flowing through the senses of the player. When users become conscious of their presence in a space, the safe position of the voyeur which is typical in cinema is overcome, and this triggers most of the motor, 
chemical and biological responses brought about by the awareness of being actually and physically present somewhere. Moreover, force-feedback interfaces which vibrate at the player's hands signal the shocks suffered by the body's muscles during the fights, thus allowing the users to experience a primitive feeling of proprioception in a fictional context. It may suffice to look at the way videoplayers move, wriggle or even writhe while playing according to the movements of their avatar, as if virtual space affected them not just at a visual level, but also at a physical level. Of course, an avatar placed in a desert is not enough to make one feel hot. What can indeed be activated are those feelings deriving from the awareness of being actually present somewhere. Such as fear for one's own safety, for example, from which all the efforts to make virtual space not simply secure, but also as pleasurable and enjoyable as possible, follow.

\section{Affective maps}

When the Arab enemy shows up on the screen, the digital apparatus works to make the player startle: comrades scream to signal the incoming menace; the wounds suffered, transmitted haptically by way of force-feedback means of input, stain images with blood, blur them, cause them to fade away making it harder for the player to see; the body movements are temporarily compromised. The interface works to make the player feel the malaise, the sense of unease and hindrance felt by the avatar at the Muslim presence. It purposely short-circuits and impairs itself in order to convey an undesirable existential condition, and users are prompted to end such an unpleasurable state if they want the interface to work correctly again. Not only must they put an end to it if they are to proceed, but they are made to wish for it. Their only choice is to keep the enemy away or slay him, since 'he' is the cause of their decay. Images, sound and haptic feedback are synesthetized in a state of promptness to strike. The screen is not just a canvas capable of gathering visual impressions, but it functions as a living tissue bound to the body's capacity to feel at a visceral level. Depending on the circumstances, it can become soaked with sensations, letting itself be traversed by the affective intensities which hit and circulate in a body when it comes into contact with certain objects and subjects in a given environment, or when it finds itself in specific situations. What is seen on screen is not a mere representation, but a transmission of affects in the threefold meaning of the term which Lone Bertelsen and Andrew Murphie summarize as follows:

The first is affect as transitive, as the movement of impersonal, or we could say prepersonal forces, in which we are caught up [...]. The second aspect is affect [...] as emotion or feeling, the folding of broader affective intensities into the nervous system, eventually to become $[. .$.$] the representation, of the ongoing folding of self and world,$ as the person. Emotion involves physical states (heat, increased heartbeat, in anger, trembling in terror). Feelings are complex strings of ideas traversing emotions as they remap them. The third aspect of affect perhaps lies in-between the other two. This is the Spinozan power to affect and be affected "by which the power of acting of the body 
itself is increased, diminished, helped, or hindered, together with the ideas of these affections." (2010: 214)

In Kuma War and America's Army, the absence of montage is thus only apparent, it works at a level which is invisible to the eye: it does not work with the images, but inbetween them, in the gap necessary for them to follow one another. Images, that is, must be understood as textures of colour pixels whose combination, recombination and variation in intensity make the biological body perform in a digital context which enforces a Manichaean opposition (or opposing complementarity) between already constituted gendered and racialized subjectivities occupying contrasting zones of mutual exclusivity. The interface in FPSes hides forms of control and drives behaviours reminiscent of colonialism by leveraging the culturally constituted male disposition to strike.

These games' virtual realities represent what Nick Dyer-Witheford defines 'militainment' (2002), one of the two main instruments of power and social control, the other being the 'ludocapitalism' of the new Empire in the digital age. They function as a means of virtual training, political propaganda and cultural indoctrination by linking together game and reality, body and avatar, space and performance, screen and agency. They succeed in absorbing, as Massumi would say, the powers of existence at the moment of their emergence, when movement's effects on the players are 'contagious', "a term that is defined as the rapid spread of influence or emotion from one body to another, but that also suggests pollution and disease" (Foster, 2008: 46). Agency is not so much the consequence of users' choice - neither is it strictly imposed or prescribed as it is induced. In the words of Tiziana Terranova:

[...] the cultural politics of information does not address so much the threat of 'disembodiment', or the disappearance of the body, but its microdissection and modulation, as it is split and decomposed into segments of variable and adjustable sizes (race, gender, sexual preferences; but also income, demographics, cultural preferences and interests). It is at this point that we can notice the convergence of the cultural politics of information with digital techniques of decomposition and recombination. For Pierre Levy, "digitisation is the absolute of montage, montage affecting the tiniest fragments of a message [...]." (2004: 34)

We can now see why this kind of videogames is one of the favourite means of propaganda used by the Department of Defence of the United States. It defines orbits not simply the grids Foucault described so well - around which behaviours and modalities for classification are modulated procedurally. It is a kind of soft control (Terranova, 2004) which works not by disciplining specific subjects, but by anticipating them. Such subjects are what Deleuze (1995) foresaw as 'dividuals', statistically configured in groups of people or populations which are addressed as "bodily capacities" - in terms of both what they can do and what it is hoped or expected they do - and targeted especially in their leisure time. In this sense, it may be useful to refer to Patricia Clough's definition of the biomediated body. In her words: 
The biomediated body is a definition of a body and what it can do - its affect - that points to the political economic and theoretical investment in the self-organization inherent to matter or matter's capacity to be in-formational, to give bodily form. More importantly, the biomediated body exposes how digital technologies [...] attach to and expand the informational substrate of bodily matter and matter generally, and thereby mark the introduction of a 'postbiological threshold' into 'life itself.' (2010: 317-318)

In these games territory is transformed into movement, which is not "given as object but always as intense repetition" (Guattari, 1995: 28). These territories allow only certain kinds of standardized movements and behaviours so that hierarchies of power remain unchanged. They manage, in Guattari's words, to "neuroleptize subjectivity" (1996: 215) by affecting or taking hold of our nervous system. To paraphrase Massumi, such an interface can be compared to a field of exteriority whose operative logic combines ontological with epistemological aspects in such a way so as to endow itself with powers of self-self-causation. That is, affects deriving from the awareness of inhabiting a given space, even if virtually (ontological aspect), prompt a kind of agency (epistemological aspect) legitimizing the very same cultural premise which set those affects in motion in the first place.

It is at this moment that the narrative logic is short-circuited and affective intensities can be easily modulated into recognizable cultural feelings, knowledge and behaviours. Muslims, in particular, become signs of fear and evil, which will always be intrinsically menacing, as they are involved in situations of irrational violence which is antithetical to Western forms of civilization. These games are part of those discourses "which tend to make aggressiveness the basis of the territory" (Deleuze and Guattari, 1987: 315). Muslims are framed and perceived as hostile agents, as a negative force in a malevolent territory whose main features are aggressiveness and violence.

Both Kuma/War! and America's Army, together with a whole lot of other first person shooters, offer three-dimensional reconstructions of existing cities and regions in the Middle East. Forterra Systems Inc., a developer of training games for the American army, declared in an interview that they had digitally "built a portion of the downtown area of a large Middle Eastern capital city" where the US "have a significant presence today." "As another example, the Evans \& Sutherland Environment Processor (EP) allows an almost real-time updating of such an environmental database, used in strategic military simulations, by means of video-recordings and satellite images taken during actual missions. Thus, every new US mission which is being carried out in the Middle East is used to acquire information to expand those databases.

However, the real technological effort here consists in the creation of templates or ready-made models, textures and structures. This is a critical issue which is of vital concern to both developers and the military sector. All data stored in those digital databases are classified and arranged in such a way so as to easily keep 3D simulations up to date and to make any kind of revision as quickly implemented as possible. Indeed, a great deal of the North-African surface is being digitally reconstructed and stored in huge archives of fear in order to turn Muslim material and social reality into a warfare 
battleground for the entertainment of Western players. A whole new generation of prospective soldiers can be made to move around in cities like Kabul, Baghdad and Freetown without even setting foot on them.

What is striking is that space is constantly dehumanized, reduced to a place for war engagement. The notions of space and place are here being used according to Tim Cresswell's definition which sees place as "a meaningful portion of space" (2006: 356). Place is a particular location of space, the unique 'where' we think things are or happen. From this perspective, what distinguishes a place from space is the 'sense' the human body feels of a given place, the particular emotions and behaviours triggered by sensorial impressions or memory when we think of it. Consequently, place is properly a way of being in the world and, as Cresswell explains, some senses of place "are likely to be the product of mediation" (356). The behavioural routines elicited in FPS games make space become "collections of objects not congeries of people" (Gregory, 2004: 201). Everyday places and objects are militarized, and all the elements present in the environment must be employed tactically to serve warfare's strategic needs. The Middle East experienced in these virtual geographies is made of labyrinthine alleys and streets, buildings in ruins, suspicious corners. It is a place infested by Muslims or terrorists (who, as previously stated, in these games amount to the same thing) conceived as inferior, subhuman creatures, bare life or as Agamben's homines sacri (1998), in need of American cleansing or even sanitizing. One of the missions in Kuma/War! sees American Marines fighting against "militant followers of radical Shiite cleric Muqtada al-Sadr in the filthy urban slum that is Sadr City", which in a sinister way reminds Frantz Fanon, when he denounced the way Western rhetoric presented North-African cities as inhabited by "niggers and dirty arabs" (2004: 30).

If Edward Said (1978) spoke of 'imaginative geographies' that produced a colonial view of the Orient as an open, virgin territory with no ability for organized rule and government, now digital technologies allow the reconstruction of virtual geographies which are more similar to Guattari's existential territories (1995). These territories are brought to existence thanks to the continual modulation of affects which are "cycled back" (Deleuze and Guattari, 1987: xv) in obsessive and alienating loops. What these virtual geographies allow is not merely a representation of space, but a situational practice of space. They represent a new kind of map, that can be called performative affective, as it is a mapping of ethos, to use an expression by Bateson, which modulates "a definite set of sentiments towards the world" (1958: 119), or Jacques Rancière's "distribution of the sensible" (2006: 13). Affective maps do not simply serve the purpose of allowing orientation in space as a virtual training ground for prospective soldiers before they are actually sent to war. They provide them with a phenomenic experience of space, so that this can function on the three levels described by Henry Lefebvre: space as it is perceived, conceived and lived (1991: 33). A space of ideological and above all cultural positioning. If, as Jean Baudrillard (1995) noted, in the pre-modern era territory preceded maps, that is its cartographic depictions, now affective maps precede territory. They allow to anticipate and lead the subject's positions, movements and behaviours not just on a physical level, but also on an 
emotional and cultural level. Even more importantly, such maps serve the purpose of modulating any possible act or performance of the players who will move in that territory. They are not static maps like the old ones, but are based on movement: they are virtual in so far as they can and must contain any possible variation of users' movements and feelings.

\section{Notes}

1. The plan was known as CONCEPT PLAN 8022.

2. The full video is available online at http://www.youtube.com/watch?v=nE3mJGIdM90 (accessed 23 September 2013).

3. Born on April 26 1963, Jessica Dawn Lynch is a former United States Army soldier who was rescued after being captured by Iraqi forces while serving in the 2003 Iraqi invasion by U.S. and allied forces.

4. PEO STRI, previously known as STRICOM.

5. The full interview is available online at:

http://www.temple.edu/ispr/examples/ex04_03_08.html (accessed 5 March 2010).

\section{References}

Agamben, Giorgio (1998): Homo Sacer: Sovereign Power and Bare Life. Stanford: Stanford University Press.

Bateson, Gregory (1958): Naven. Stanford: Stanford University Press.

Baudrillard, Jean (1995): “The Map Precedes the Territory.” In W. T. Anderson, ed., The Truth About The Truth. De-Confusing and Re-Constructing the Postmodern World. New York: Putnam's Sons, 79-82.

Bertelsen, Lone and Andrew Murphie (2010): “An Ethics of Everyday Infinities and Powers." In Melissa Gregg and G. J. Seigworth, eds., The Affect Theory Reader. Durham: Duke University Press, 211-241.

Butler, Judith (1997): Excitable Speech. A Politics of the Performative. London: Routledge.

Callaham, John (2004): Army Massively Multiplayer. Project Interview. http://www.temple.edu/ispr/examples/ex04_03_08.html (accessed 5 March 2010).

Clough, Patricia Ticineto (2010): "The Affective Turn: Political Economy, Biomedia, and Bodies." In Melissa Gregg and G. J. Seigworth, eds., The Affect Theory Reader. Durham: Duke University Press, 316-345.

Connolly, William E. (2002): Neuropolitics. Thinking, Culture, Speed. Minneapolis: University of Minnesota Press.

Cresswell, Tim (2006): "Place." In Barney Warf, ed., Encyclopaedia of Human Geography. Thousand Oaks/London: Sage Publications, 356-358.

Deleuze, Gilles (1992): "Postscript on the Control Societies." October 59: 3-7.

- (1995) Negotiations, 1972-1990. New York: Columbia University Press.

Deleuze, Gilles and Felix Guattari (1987): A Thousand Plateaus: Capitalism and Schizophrenia. Minneapolis: University of Minnesota Press.

Derrida, Jacques (1977): Limited Inc. Evanston: Northwestern University Press. 
Dyer-Witheford, Nick and Greig de Peuter (2009): Games of Empire. Global Capitalism and Videogames. Minneapolis/London: University of Minnesota Press.

Foster, Susan Leigh (2008): "Movement's Contagion. The Kinaesthetic Impact of Performance." In T. C. Davis, ed., The Cambridge Companion to Performance Studies. Cambridge: Cambridge University Press, 46-59.

Galloway, Alexander (2004): Protocol: How Control Exists after Decentralization. Cambridge, Massachusetts: The MIT Press.

- (2006): Gaming. Essays on Algorithmic Culture. Minneapolis: University of Minnesota Press.

Goffman, Erving (1956): The Presentation of Self in Everyday Life. Edinburgh: University of Edinburgh Social Sciences Research Centre.

Gregory, Derek (2004): The Colonial Present. Oxford UK: Blackwell.

Fanon, Frantz (2004): The Wretched of the Earth. New York: Grove Press.

Guattari, Felix (1995): Chaosmosis: An Ethico-aesthetic Paradigm. Bloomington: Indiana University Press.

- (1996): Soft Subversions. New York: Semiotext(e).

Hansen, Mark (2006): Bodies in Code: Interfaces with Digital Media. New York and London: Routledge.

Korris, James H. (2007): "Ender's Game. Toward a Synthetic View of the World." In Friedrich von Borries et al., eds., Space, Time, Play. Computer Space, Architecture and Urbanism: The Next Level. Basel: Birkhäuser Verlag AG, 425-429.

Lefebvre, Henri (1991): The Production of Space. Oxford: Blackwell.

Massumi, Brian (2002): Parables for the Virtual: Movement, Affect, Sensation. Durham, N.C.: Duke University Press.

- (2011): Semblance and Event. Activist Philosophy and the Occurrent Arts. Cambridge, Massachusetts: The MIT Press.

McLuhan, Marshall (1964): Understanding Media: The Extensions of Man. New York: McGraw-Hill.

Peirce, Charles S. (1988): The Essential Peirce, Vol. 2. Indianapolis: Indiana University Press.

Ranciére, Jacques (2006): The Politics of Aesthetics: The Distribution of the Sensible. London: Continuum.

Said, Edward (1978): Orientalism. London: Routledge \& Kegan Paul.

Shaviro, Steven (1993): The Cinematic Body. Minneapolis: University of Minnesota Press.

Terranova, Tiziana (2004): Network Culture: Politics for the Information Age. London: Pluto Press. 